\title{
Review of Estimation Method of Economic Effects Created by Using Open Data
}

\author{
Tetsuo Noda \\ Shimane University \\ Nishikawatsu-cho 1060 \\ Matsue City, Shimane, \\ Japan \\ +81-852-32-6164 \\ nodat@soc.shimane-u.ac.jp
}

\author{
Masami Honda \\ Shimane University \\ Nishikawatsu-cho 1060 \\ Matsue City, Shimane, \\ Japan \\ +81-852-32-9700 \\ ask@honda-masami.jp
}

\author{
Akio Yoshida \\ Independent \\ Kawabe-cho 8-9-22 \\ Oume City, Tokyo \\ Japan \\ +81-428-1457 \\ akio.yoshida@gmail.com
}

\author{
Shane Coughlan \\ Opendawn \\ B201 RoyalParks \\ Hayashi-cho 165 \\ Takamatsu-Shi, Kagawa, \\ +81-80-4035-8083 \\ shane@opendawn.com
}

\begin{abstract}
Public data collected or possessed by administrative agencies and subsequently released as Open Data is expected to bring about positive economic effects. The purpose of this paper is to establish whether that expectation holds true and how to best estimate the positive economic effect provided by the utilization of open data. This paper considers previous research covering the economic impact of open data and the utility of the approaches they suggest.
\end{abstract}

\section{CCS Concepts}

- Proper nouns: People, technologies and companies $\rightarrow$ Organizations $\rightarrow$ Open Knowledge Society

\section{Keywords}

Open Data; Economic Effect; Open Innovation; Public Data; Public Sector Information; Spatial Information Technology; General Equilibrium Model

\section{INTRODUCTION}

Public data collected or possessed by administrative agencies and subsequently released as Open Data is expected to bring about positive economic effects. There is some investigative research of this economic area by the EU European Commission, national governments, and private research institutes. However, each research method to date has largely depended on philological style and their conclusions are not reviewed from the perspective of directly gathering Open Data. Because of this the defined range of Open Data and its definitions of application vary widely. Though this paper is also philological, we consider the two points before estimating economic effects suggested by the utilization of Open Data. The one is the range of Open Data and the definition of its application. The other is the desired effect by the utilization of Open Data and the estimation method of this effect.

Permission to make digital or hard copies of all or part of this work for personal or classroom use is granted without fee provided that copies are not made or distributed for profit or commercial advantage and that copies bear this notice and the full citation on the first page. Copyrights for components of this work owned by others than the author(s) must be honored. Abstracting with credit is permitted. To copy otherwise, or republish, to post on servers or to redistribute to lists, requires prior specific permission and/or a fee. Request permissions from Permissions@acm.org.

OpenSym '16 Companion, August 17 - 19, 2016, Berlin, Germany

Copyright is held by the owner/author(s). Publication rights licensed to $A C M$.

ACM 978-1-4503-4481-4/16/08 ..\$15.00

DOI: http://dx.doi.org/10.1145/2962132.2962144

\section{An Estimate of the Economic Effect of Open Public Data}

\subsection{ACIL Tasman research $(2008,2009)$}

ACIL Tasman's investigation research is not intended to estimate economic effect of Open Data directly but to explore how modern spatial information technologies have impacted economic activities. ACIL Tasman (2008) covers the Australian economy, and ACIL Tasman (2009) covers the New Zealand's economy. ACIL Tasman (2008) estimates scales of total sales of sectors utilizing modern spatial information technology, effects of productivity growth of these sectors (effect gained by cost reductions and revenue increases in sectors which utilize modern spatial information technology), and economic ripple effect sparked by this productivity growth of Australian economy. It does this by conducting interviews with various industries using modern spatial information technologies. ACIL Tasman (2009) investigates New Zealand's economy using the same method. The research approach applied is to measure what percentage such technologies contribute to cost reductions and revenue increases for relevant industries versus the cost reductions and revenue increases provided by maintaining a proprietary approach. These accumulated economic effects in various sectors are then explored. An illustrative example is found in the forestry, iron ore, and gas industries where (1) there is a combined 1.37 billion AUD invested in modern spatial information technologies, (2) which provide a $0 \sim 7 \%$ (minimum scenario) or $0.02 \sim 14 \%$ (maximal scenario) impact on productivity growth (3) with a total economic ripple effect of $6.43 \sim 12.57$ billion AUD (0.6 1.2\% of GDP) (4) and have passive cost from not opening data of an estimated $7.5 \%$ of 6.43 billion AUD.

While the subject of the ACIL Tasman's investigation research is limited to the utilizations of modern spatial information technologies it is concerned with the economic effect provided by the utilization of data gathered, reprocessed, and opened from government and private sources. This is decisive either way with regards the utilization of Open Data but it provides some indirect indicators that may be usefully considered. The research also adopts the method of estimating passive damages from proprietary data associated with modern spatial information technologies. If we read this data and this approach as true then the economic effect of opening data in modern spatial information technologies should be construed as $0.045 \sim 0.09 \%$ of GDP with respect to its total economic ripple effect and passive cost.

It should be noted that the research adopted the Computable General Equilibrium Model to estimate the total economic ripple effect. This model analyzes modifications of relationships among industrial sectors caused by the direct economic effect of Open Data, for example, some sectors' there was an increase of production volume caused by cost reductions of resources from 
other sectors, and it ultimately shows how these modifications can impact the overall economy.

\subsection{The EU European Commission Vickery Research (2011)}

The European Commission Vickery research project explored the economic effects of Open Data via Public Sector Information within EU 27 countries. The study is philological in approach and significantly depends on estimated figures extrapolated from the prior ASIL Tasman investigation. Because of this the estimates are not analyzed from gathered data. Instead Vickery (2011) estimates economic effects by applying estimated data derived from Tasman into the GDP data from the EU 27 then averaging the total.

Despite the fact that ASIL Tasman's research only estimates the economic effects of modern spatial information technologies the Vickery investigation seeks to extrapolate the overall utilization of data across public administrations. It converts data from public sector into what it terms a Public Service Information (PSI) value. This estimates how data can drive economic value in departmental sectors and from a cross-sector perspective. It proceeds to consider direct economic effects of data and the economic effect when such data is opened. The conclusion is that PSI Data has a nominal value of 140 billion Euro annually across the EU 27 and the economic effect of opening this data is worth approximately 200 billion Euro annually or $1.7 \%$ of GDP across the EU. The latter estimation is assumed to be the result of passive benefits along similar lines to the ASIL Tasman research.

It is no surprise that Vickery has results in-line with Tasman given its inheritance of the previous research approach and assumptions. This provides the potential for biases or faults in that research works to be inherited. Additionally, it means that industrial structure or cross-sector relationships that differ between the EU 27 and Australia or New Zealand are not considered. It is therefore with some hesitation that we must consider the outcomes of the Vickery investigation, including its conclusion that passive damages from failing to open data may have a passive ripple effect that constitutes up to $7.5 \%$ of the 200 billion Euro otherwise obtained, though we cannot discount there conclusions.

\subsection{Innovation Nippon Workshop Report (2013)}

The Innovation Nippon Workshop Report (2013) estimates the economic effects of Open Data in Japan using Tasman as the basis for its considerations. Its conclusions are that the direct economic effect of PSI data are equal to 16 31.4 billion Euro (0.51\% 0.99\% of GDP) annually in Japan with an additional economic effect when PSI data is opened equivalent 1.2 2.3 billion Euro annually. This means that the additional economic effect of Open Data is $0.04 \% \sim 0.07 \%$ of GDP and in-line with the ACIL Tasman research conclusions.

The government has attached significant policy importance to Open Data in Japan and has taken measures such as the 'Electronic Administrative Open Data Policy' in 2012 to support its growth. Unfortunately there is little data to estimate the effect of such policy at this juncture due to there being little data unpacking Open Data itself. This lack of direct source material is perhaps the reason why economic effects have been estimated using prior research conclusions rather than providing direct source material and a targeted local market research approach. It does not invalidate the conclusions but it is worthy of note and suggests avenues for future research.

\section{Challenges in the Estimation Methods Applied to Economic Effects}

3.1 The Use of Previous Research Conclusions

It is possible to estimate the economic effects created by the utilization of open data in the public sector. However, policy in support of open data is relatively new and this limits the scope of reliable information available. This in turn impacts Macroeconomic approaches such as the application of the growth accounting method. The only available avenue to address this issue is to obtain such information via conducting interviews and/or undertake questionnaire surveys with administrate agencies and private industry bodies that use Open Data in each target country. The precise questions applied can be varied but are likely to include some combination of (a) consideration regarding the quantity of collected data, (b) the percentage of its utilization, (c) obstacles preventing open data in the target sector and/or country, (d) risks perceived by opened data and (e) the possibility of business expansion provided by Open Data. This follows the research approach originally undertaken by ACIL Tasman but requires vast amounts of time and effort to reapply to new markets and countries from first principles. For this reason subsequent research has followed the conclusions of the original work, applying its parameters to their research targets, with an assumption of similar percentages of sector and GDP impact remaining true. Vickery (2011) and Innovation Nippon Workshop Report (2013) are two such research initiatives that adopt these estimated. However, this also makes them susceptible to biases or faults in the previous research work and challenges regarding differences in the economic subjects covered.

\subsection{Estimating the Economic Effect of Using Open Data}

To estimate economic effect of Open Data of each country in a scientific manner we must start from the measurable effect of past policy regarding Open Data. ACIL Tasman's research serves as a valuable reference in this respect. From this starting point research can proceed to interview industry participants using Open Data and measuring what percent these technologies contribute to cost reductions and revenue increases and to what percent relevant industry sectors lose cost reductions and revenue increases by failing to open such data. Ideally this should be done by taking into account the particular parameters and coefficients in various sectors of each country. This then allows to estimate the economic effect of using Open Data by accumulating the measured economic effects in each relevant sectors. What is important to note is that ACIL Tasman's research is not a panacea in this respect. It was focused not on Open Data but on modern spatial information technology. Moving forward researchers should ideally define the definition and applicable area of Open Data to enhance the fidelity of their results.

\subsubsection{Defining Open Data}

In previous studies the subjects of research included not only data provided by public institutions but also data opened from other organizations, industries and individuals. While such data may have an economic effect it needs to be isolated in research if one of the desired outcomes is to validate the direct effects of policy activities by national and local governments. In our case we therefore define Open Data as data "opened" from public data sources owned by national and local governments.

It can then be assumed that such public data is utilized in corresponding industry sectors and subsequently accumulates 
measurable economic effects there and in adjacent sectors, resulting in an economic ripple effect and passive damages. as observed in ACIL Tasman and assumed in later research.

\subsubsection{Economic effects and estimation method}

To estimate the economic effects quantitatively sources of (a) public data, (b) the ratio of opened data, (c) and the cost to open data are needed. For public sector organizations opening data is likely to be an initial cost-center with the expectation of positive economic effects such as improved public services or market creation to offset such costs in the mid-to-long term.

For commercial industries the presumed impact is cost reduction considered in the following manner: (d) cost reduction by using open public data, (e) economic losses by data not opened, (f) and the economic effect of using other means of obtaining data in such a situation. These are direct economic effects that can be potentially leveraged by businesses to improve their competitiveness to obtain (g) market expansion, (h) the creation of new business markets or (i) changes in industrial structures. These processes are visualized in Figure 1.

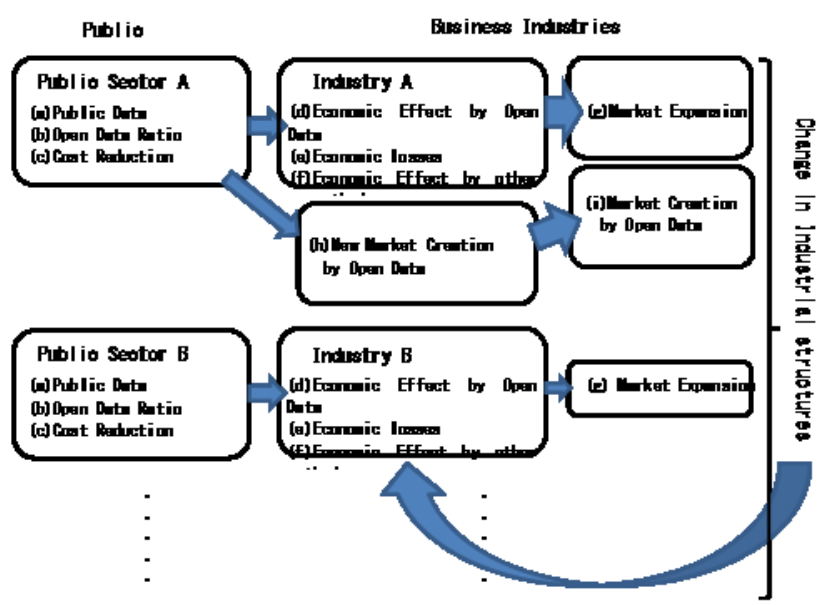

Figure 1. Economic effects by the utilization of Open Data

\section{The Outlook of Further Research}

To estimate the economic effect obtained by the utilization of Open Data we considered previous research. While there is value in this work, particularly in the foundation provided by ACIL Tasman, there is identified utility in seeking to more clearly define Open Source and in obtaining direct research data from the target industries in the local economic market being reviewed. For this reason our research has a clear definition regard the utilization of Open Data and an equally clear understanding for how its estimation core data can be best obtained. We are proceeding to estimate the economic effect offered by the utilization of open data in Japan using quantitative data obtained by survey. It is structured as per Figure 1 and is initially being applied to national and local governments in this nation. This process requires a significant amount of time and effort but is underway and we hope to provide conclusions regarding measurable local market economic effects in the near future.

\section{REFERENCES}

[1] ACIL Tasman. 2008. The value of spatial information: The impact of modern spatial information technologies on the Australian economy, report prepared for the CRC for Spatial Information and ANZLIC, Australia, the Spatial Information Council.

$<$ http://www.crcsi.com.au/Documents/ACILTasmanReport_f ull.aspx $>$ Accessed 2016, April 1.

[2] ACIL Tasman .2009. Spatial information in the New Zealand economy: Realizing productivity gains, a report prepared for Land Information New Zealand; Department of Conservation; Ministry of Economic Development.

$<$ http://www.crcsi.com.au/Documents/spatial-information-inthe-new-zealand-economy-200.aspx $>$ Accessed 2016, April 1 .

[3] McKinsey Global Institute. 2011. Big data: The next frontier for innovation, competition, and productivity. $<$ http://www.mckinsey.com/insights/business_technology/bi g_data_the_next_frontier_for_innovation> Accessed 2016, April 1.

[4] McKinsey Global Institute. 2013. Open data: Unlocking innovation and performance with liquid information. $<$ http://www.mckinsey.com/insights/business_technology/op en_data_unlocking_innovation_and_performance_with_liqui d_information> Accessed 2016, April 1

[5] MEPSIR: Measuring European Public Sector Information Resources. 2006. Final Report of Study on Exploitation of public sector information - benchmarking of EU framework conditions.

$<$ http://www.ec.europe.eu/information_society/newsroom/cf/ /document.cfm?doc_id=1198> Accessed 2016, April 1.

[6] Omidyar Network. 2014. Open for Business: How Open Data Can Help Achieve the G20 Growth Target.

$<$ http://www.omidyar.com/sites/default/files/file_archive/insi ghts/ON\%20Report_061114_FNL.pdf $>$ Accessed 2016, April 1.

[7] Open Knowledge Foundation. 2013. Open Data Census 2013 by Open Knowledge Foundation.

$<$ http://blog.okfn.org/2013/02/20/open-data-census-trackingthe-state-of-open-data-around-the-world/> Accessed 2016, April 1.

[8] Pollock. Undated. Welfare gains from opening up Public Sector Information in the UK, University of Cambridge", undated.

$<$ http://rufuspollock.org/economics/papers/psi_openness_gai ns.pdf $>$ Accessed 2016, April 1.

[9] Vickery, G. 2011. Review of recent studies on PSI re-use and related market developments.

$<\mathrm{http}$ ://ec.europa.eu/information_society/newsroom/cf//docu ment.cfm?doc_id=1093> Accessed 2016, April 1. 